\title{
Treatment Compliance with Fixed-Dose Combination of Vildagliptin/Metformin in Patients with Type 2 Diabetes Mellitus Inadequately Controlled with Metformin Monotherapy: A 24-Week Observational Study
}

\author{
Grigorios Rombopoulos, ${ }^{1}$ Magdalini Hatzikou, ${ }^{1}$ \\ Athanasios Athanasiadis, ${ }^{2}$ and Moyses Elisaf ${ }^{3}$ \\ ${ }^{1}$ Novartis Hellas S.A., 12 th klm National Road 1, Metamorfosis, 14451 Athens, Greece \\ ${ }^{2}$ Foundation for Economic and Industrial Research (IOBE), 11 Tsami Karatatsi Street, 11742 Athens, Greece \\ ${ }^{3}$ University Hospital of Ioannina, Stavros Niarchos Avenue, 45500 Ioannina, Greece \\ Correspondence should be addressed to Grigorios Rombopoulos; grigorios.rombopoulos@novartis.com
}

Received 26 August 2014; Accepted 26 September 2014

Academic Editor: Ilias Migdalis

Copyright (C) 2015 Grigorios Rombopoulos et al. This is an open access article distributed under the Creative Commons Attribution License, which permits unrestricted use, distribution, and reproduction in any medium, provided the original work is properly cited.

Objective. To evaluate the differences in treatment compliance with vildagliptin/metformin fixed-dose versus free-dose combination therapy in patients with type 2 diabetes mellitus (T2DM) in Greece. Design. Adult patients with T2DM, inadequately controlled with metformin monotherapy, ( $850 \mathrm{mg}$ bid), participated in this 24 -week, multicenter, observational study. Patients were enrolled in two cohorts: vildagliptin/metformin fixed-dose combination (group A) and vildagliptin metformin free-dose combination (group B). Results. 659 patients were enrolled, 360 were male, with mean BMI 30.1, mean T2DM duration 59.6 months, and mean HbAlc at baseline 8\%; 366 patients were assigned to group A and 293 to group B; data for 3 patients was missing. In group A, 98.9\% of patients were compliant with their treatment compared to $84.6 \%$ of group B. The odds ratio for compliance in group A versus B was (OR) 18.9 (95\% CI: 6.2, 57.7; $P<0.001)$. In group A mean HbAlc decreased from $8.1 \%$ at baseline to $6.9 \%(P<0.001)$ at the study end and from $7.9 \%$ to $6.8 \%(P<0.001)$ in group B. Conclusions. Patients in group A were more compliant than patients in group $B$. These results are in accordance with international literature suggesting that fixed-dose combination therapies lead to increased compliance to treatment.

\section{Introduction}

Type 2 diabetes mellitus (T2DM) is a chronic, progressive disease. As glycemic control deteriorates over time, treatment intensification with the addition of multiple oral antihyperglycemic agents is often required in patients inadequately controlled with monotherapy [1]. Polypharmacy and complexity of the treatment regimens are associated with poor adherence to treatment, which in turn is associated with inadequate glycemic control [2-4]. On the other hand, the use of a fixed-dose combination of agents with complementary mechanisms of action is associated with improved patient compliance and adherence to treatment, as well as better glycemic control $[5,6]$.
Vildagliptin is a potent and selective oral dipeptidyl peptidase-4 inhibitor that improves glycemic control in patients with T2DM by increasing both the $\alpha$-cell and $\beta$-cell responsiveness to glucose $[7,8]$. In numerous clinical trials, combination therapy with vildagliptin and metformin has demonstrated a better efficacy and safety profile with good gastrointestinal tolerability than high-dose metformin monotherapy $[9,10]$. A single-pill combination of vildagliptin/metformin has been approved in the European Union and across many countries in the world for the treatment of patients with T2DM inadequately controlled with metformin alone [11]. In the present study, we evaluated the differences in the treatment compliance with vildagliptin/metformin fixed-dose combination and vildagliptin (50 $\mathrm{mg}$ bid) added to metformin 
(free-dose combination) therapy in patients with T2DM in Greece.

\section{Materials and Methods}

This was a 24-week, multicenter, observational study. Patients aged $>18$ years with T2DM and inadequate glycemic control with metformin monotherapy ( $850 \mathrm{mg}$ bid) were eligible to participate in the study. Patients were enrolled in two cohorts on 1:1 ratio, according to everyday clinical practice: those receiving either vildagliptin/metformin fixed-dose combination pill (hereafter referred to as the fixed-dose combination group) or vildagliptin (50 mg bid) added to metformin (850 mg bid) (hereafter referred to as the free-dose combination group).

Patients with a history of type 1 diabetes, end stage renal disease, undergoing hemodialysis, congestive heart failure, and pregnant or lactating women were excluded from the study. In order to assess the treatment compliance, investigators were asked to complete a compliance questionnaire by interviewing patients both at the baseline (visit 1) and final visit 3 (24 weeks after baseline) (Table 1). Patients were considered compliant if they did not miss any drug dose or no more than 2 doses per week, received the correct dosage of the medication, and did not interrupt their treatment. Treatment compliance was assessed from the compliance questionnaire, and the difference in compliance between the treatment groups was reported. In addition to the questionnaire, investigator collected clinical, demographic, and relevant medical history data including comorbidities and complications. At the baseline visit, each patient was given a diary to record their medication intake on a daily basis. The patient was asked to return this diary to the physician at the final visit.

The study was designed and conducted in accordance with the applicable local regulations and with the ethical principles laid down in the Declaration of Helsinki. A written, informed consent was requested from each patient before enrollment in the study.

2.1. Efficacy and Safety Assessments. The primary objective was to compare the percentage of patients compliant with their prescribed therapy. Secondary objectives of the study were to assess the changes in the levels of HbAlc from the baseline until the end of the study (day 0 to 6 months after) and to assess the safety and tolerability profile of vildagliptin.

2.2. Statistical Analysis. Assuming $60 \%$ of the patients on fixed-dose combination therapy were compliant and a difference in the treatment groups of $12 \%, 320$ patients per treatment group were required to provide $90 \%$ power at a significance level of $5 \%$. The primary variable, difference in compliance between the two treatment groups, was assessed using a multiple binary logistic regression model and adjusted for age, sex, comorbidities, concomitant medications, duration of T2DM, whether patients remembered the names of their medications for T2DM, difficulties in ingestion, and clinical laboratory test results.
TABLE 1: Compliance questionnaire.

\begin{tabular}{|c|c|}
\hline Variable & \\
\hline \multirow{3}{*}{$\begin{array}{l}\text { Does the therapy affect the daily activities } \\
\text { of the patient? }\end{array}$} & In acute degree \\
\hline & In some degree \\
\hline & No \\
\hline \multirow{2}{*}{$\begin{array}{l}\text { Taking their medication at the same time } \\
\text { every day? }\end{array}$} & Yes \\
\hline & No \\
\hline \multirow{2}{*}{$\begin{array}{l}\text { Does the patient have difficulties in } \\
\text { swallowing the medication? }\end{array}$} & Yes \\
\hline & No \\
\hline \multirow{3}{*}{$\begin{array}{l}\text { How important do you consider that the } \\
\text { therapy is in order to treat the disease? }\end{array}$} & Very important \\
\hline & Important \\
\hline & Of some importance \\
\hline \multirow{6}{*}{$\begin{array}{l}\text { Have they missed any dose of the } \\
\text { treatment? }\end{array}$} & Today \\
\hline & Yesterday \\
\hline & Last week \\
\hline & Last 2 weeks \\
\hline & Last month \\
\hline & Not one dose \\
\hline \multirow{2}{*}{$\begin{array}{l}\text { Percentage of medication received last } \\
\text { month. }\end{array}$} & Mean \\
\hline & SD \\
\hline \multirow{2}{*}{$\begin{array}{l}\text { Does the patient remember the } \\
\text { commercial names of the medications? }\end{array}$} & Yes \\
\hline & No \\
\hline \multirow{2}{*}{$\begin{array}{l}\text { Total number of daily tablets for the } \\
\text { treatment of T2DM. }\end{array}$} & Mean \\
\hline & $\mathrm{SD}$ \\
\hline \multirow{5}{*}{$\begin{array}{l}\text { How often do they forget to take their } \\
\text { treatment for T2DM. }\end{array}$} & Never/almost never \\
\hline & 1-2 times a month \\
\hline & 1 time in a week \\
\hline & $>1$ time in a week \\
\hline & Almost every day \\
\hline \multirow{2}{*}{ Compliance. } & Yes \\
\hline & No \\
\hline
\end{tabular}

The odds ratio (OR) with $95 \%$ confidence intervals (CI) was also calculated from the multiple binary logistic regression analysis. Change in HbAlc from baseline to end of study was analyzed using an analysis of covariance model (AN.CO.VA.). All adverse events (AEs) and serious adverse events (SAEs) were recorded and monitored, along with their severity and relationship to the study drug.

\section{Results}

Patient demographics and baseline characteristics were generally comparable between the two treatment groups (Table 2). Of the 659 patients enrolled, 366 (55.5\%) were assigned to the fixed-dose combination group and 293 (44.5\%) to the freedose combination group; data for 3 patients were missing. Overall, $54.4 \%$ of patients were men, mean age was 61.9 years, mean body mass index (BMI) was $30.1 \mathrm{~kg} / \mathrm{m}^{2}$, and mean baseline $\mathrm{HbAlc}$ was $8.0 \%$. About $9 \%$ of patients were taking other concomitant medications and $16 \%$ of patients had comorbidities, of which $70 \%$ of patients had hypertension, $59 \%$ had dyslipidemia, and $12 \%$ had ischemic heart disease. 
TABLE 2: Patient baseline and demographic characteristics.

\begin{tabular}{lccc}
\hline & Free-dose combination group $N=293$ & Fixed-dose combination group $N=366$ & Total $N=659$ \\
\hline Age, years & $62.0(9.6)$ & $61.9(8.7)$ & $61.9(9.1)$ \\
$\quad 60-75, n(\%)$ & $141(48.1)$ & $192(52.5)$ & $334(50.5)$ \\
$\quad>75, n(\%)$ & $23(7.8)$ & $16(4.4)$ & $39(5.9)$ \\
Gender, men, $n(\%)$ & $152(51.9)$ & $205(56.0)$ & $360(54.4)$ \\
Body mass index, kg/m ${ }^{2}$ & $29.6(3.9)$ & $30.4(4.04)$ & $30.1(4.0)$ \\
Duration of T2DM, months & $55.4(51.1)$ & $62.4(55.2)$ & $59.6(54.2)$ \\
Mean HbAlc, \% & $7.9(0.8)$ & $8.1(0.9)$ & $8.0(0.8)$ \\
Comorbidity, yes, $n(\%)$ & $54(18.4)$ & $49(13.4)$ & $104(15.7)$ \\
Concomitant treatments, yes, $n(\%)$ & $28(9.6)$ & $31(8.5)$ & $60(9.1)$ \\
\hline
\end{tabular}

T2DM, type 2 diabetes mellitus; data are presented as mean (SD) unless otherwise specified.



FIGURE 1: Percentage of patients compliant to treatment (logarithmic regression model, chi-square test).

Overall, $92.6 \%$ of patients were compliant with their prescribed therapy according to the definition of compliance used in this study.

The percentage of patients compliant with treatment in the fixed-dose combination group was $98.9 \%$ compared with $84.6 \%$ in the free-dose combination group before adjusting for confounding factors (Figure 1). The OR for compliance in the fixed-dose combination group versus the free-dose combination group was 18.9 (95\% CI: 6.2, 57.7; $P<0.001$ ) after adjusting for confounding factors. Patients who remembered the names of their medications were five times more likely to comply with their treatment than patients who did not remember the names of their medications. Patients who experienced difficulty in swallowing their medications were 31.3 times less likely to comply with their treatment compared with patients who did not experience any difficulty in swallowing their medications. The model was also tested for goodness of fit to the data of the study using the Hosmer

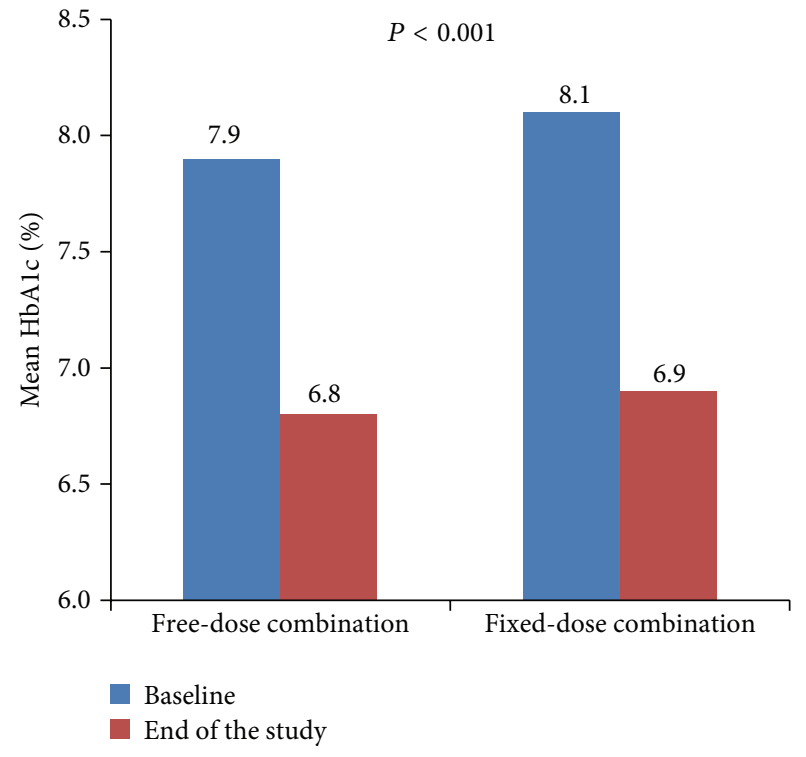

FIGURE 2: Mean HbAlc (\%) at baseline and at end of study (logarithmic regression model, chi-square test).

and Lemeshow that proved that the model had a good fit to the study data; $P$ value $=0.619$ (Table 3$)$.

The mean HbAlc decreased from a baseline of $8.1 \%$ to $6.9 \%$ in the fixed-dose combination group and from $7.9 \%$ to $6.8 \%$ in the free-dose combination group; the change was statistically significant from baseline to study end in both groups but not between groups (Figure 2). No serious AEs were reported during the study.

\section{Discussion}

Management of T2DM is complex due to multiple factors such as competing comorbidities, resistance to pharmacotherapy, reluctance to increase the dosage and/or the number of medications, low socioeconomic or educational status, and lack of adherence to lifestyle modifications [12]. All the above factors lead to poor treatment compliance. One practical way to enhance compliance in patients with multiple 
TABLE 3: Log regression model on compliance and confounding factors.

\begin{tabular}{|c|c|c|c|c|c|}
\hline \multirow{2}{*}{ Variables } & \multirow{2}{*}{$B$} & \multirow{2}{*}{$P$ value } & \multirow{2}{*}{$\operatorname{Exp}(B)$} & \multicolumn{2}{|c|}{$95 \%$ CI for $\operatorname{Exp}(B)$} \\
\hline & & & & Lower & Upper \\
\hline $\begin{array}{l}\text { Treatment (fixed } \\
\text { versus free } \\
\text { combination) }\end{array}$ & 2,938 & 0.001 & 18,887 & 6,178 & 57,738 \\
\hline $\begin{array}{l}\text { Medication recall } \\
\text { visit } 3\end{array}$ & 1,609 & 0.001 & 4,997 & 2,432 & 10,264 \\
\hline $\begin{array}{l}\text { Swallowing } \\
\text { difficulties visit } 3\end{array}$ & $-2,574$ & 0.001 & 0,076 & 0,032 & 0,184 \\
\hline Constant & 3,488 & 0.220 & 32,728 & & \\
\hline
\end{tabular}

comorbidities and receiving concomitant medications is to simplify the treatment regimen with fixed-dose combinations. Results from meta-analysis of clinical trials showed that fixed-dose combinations reduce the risk of noncompliance and improve compliance with treatment compared with freedose combination regimens $[13,14]$.

As treatment compliance may influence the overall glycemic control as well as progression of the disease, findings from this study may prove to be useful when assessing treatment strategies for diabetes mellitus. In the present observational study, more number of patients in the fixed-dose combination group were found to be compliant to the treatment (OR 18.9, 95\% CI: 6.2, 57.7; $P<0.001$ ) compared with the free-dose combination group. This is consistent with the findings from a meta-analysis of seven studies that reported $10 \%$ to $13 \%$ higher treatment adherence with fixed-dose combination of medications than with free-dose combinations [5]. In this study, patients who did not remember the names of their medications and those who experienced difficulty in swallowing their medications were less likely to comply with their treatment, suggesting that simple names for medications and pill size could help in improving the compliance with medication. The mean $\mathrm{HbAlc}$ decreased from a baseline of 8.1 to $6.9 \%$ in the fixed-dose combination group and from $7.9 \%$ to $6.8 \%$ in the free-dose combination group. The observed HbAlc drop in the present study is consistent with the results reported from a large clinical trial $(-0.9 \pm 0.1 \%)$ which assessed the efficacy and safety of vildagliptin add-on to metformin [15]. Of note, although there were differences with respect to treatment compliance between the fixed-dose and free-dose combinations, these did not result in a difference in efficacy. The results from the present study showed that the combination of two oral antihyperglycemic agents with complementary mechanisms of action offers benefits of consistent glycemic control and helps to improve medication compliance. In addition, there were no new safety signals observed with either fixed-dose or free-dose combinations of vildagliptin and metformin which was generally consistent with the previously reported tolerability profile of vildagliptin as add-on therapy to metformin [8].

The present study has certain limitations that need to be considered while interpreting the results. Only a few patients completed the diaries on a daily basis which resulted in inadequate data for additional analysis and, further, the 6month follow-up period might be considered a short duration for the measurement of compliance and its effect on efficacy. Moreover, it should be added that the method assessing compliance (interview) is not as accurate as the pill count method or the microprocessor method.

In conclusion, patients on vildagliptin/metformin fixeddose combination were more compliant with their treatment when compared with patients on free-dose combination. Taking into account that T2DM is a chronic disease, it is important to emphasize that its management should be a part of a health policy plan, and priority should be given to therapies with proven effectiveness and safety as well as fixed-dose combinations that improve patients' compliance.

\section{Conflict of Interests}

Grigorios Rombopoulos and Magdalini Hatzikou are employees of Novartis Hellas S.A., Athens, Greece; Athanasios Athanasiadis has no conflict of interests and Professor Moyses Elisaf received compensation as trial investigator from Novartis Hellas.

\section{Authors' Contribution}

Grigorios Rombopoulos was involved in designing the study protocol; Magdalini Hatzikou and Athanasios Athanasiadis have analyzed the data and Moyses Elisaf performed the final review of the study outcomes report. All authors were involved in providing inputs and reviewing of the paper.

\section{Acknowledgment}

The authors would like to thank G. Lakshmi Deepa, Ph.D. (Novartis Healthcare Private Limited, India), for medical writing support.

\section{References}

[1] S. E. Inzucchi, R. M. Bergenstal, J. B. Buse et al., "Management of hyperglycemia in type 2 diabetes: a patient-centered approach: position statement of the American Diabetes Association (ADA) and the European Association for the Study of Diabetes (EASD)," Diabetes Care, vol. 35, no. 6, pp. 1364-1379, 2012.

[2] J. M. Schectman, M. M. Nadkarni, and J. D. Voss, "The association between diabetes metabolic control and drug adherence in an indigent population," Diabetes Care, vol. 25, no. 6, pp. 10151021, 2002.

[3] M. Pladevall, L. K. Williams, L. A. Potts, G. Divine, H. Xi, and J. E. Lafata, "Clinical outcomes and adherence to medications measured by claims data in patients with diabetes," Diabetes Care, vol. 27, no. 12, pp. 2800-2805, 2004.

[4] R. A. Vigersky, "An overview of management issues in adult patients with type 2 diabetes mellitus," Journal of Diabetes Science and Technology, vol. 5, no. 2, pp. 245-250, 2011.

[5] V. Hutchins, B. Zhang, R. L. Fleurence, G. Krishnarajah, and J. Graham, "A systematic review of adherence, treatment satisfaction and costs, in fixed-dose combination regimens in type 2 
diabetes," Current Medical Research and Opinion, vol. 27, no. 6, pp. 1157-1168, 2011.

[6] S. Han, K. Iglay, M. J. Davies, Q. Zhang, and L. Radican, "Glycemic effectiveness and medication adherence with fixeddose combination or coadministered dual therapy of antihyperglycemic regimens: a meta-analysis," Current Medical Research and Opinion, vol. 28, no. 6, pp. 969-977, 2012.

[7] B. Balas, M. R. Baig, C. Watson et al., "The dipeptidyl peptidase IV inhibitor vildagliptin suppresses endogenous glucose production and enhances islet function after single-dose administration in type 2 diabetic patients," The Journal of Clinical Endocrinology and Metabolism, vol. 92, no. 4, pp. 1249-1255, 2007.

[8] B. Ahrén, J. E. Foley, and E. Bosi, "Clinical evidence and mechanistic basis for vildagliptin's action when added to metformin," Diabetes, Obesity and Metabolism, vol. 13, no. 3, pp. 193-203, 2011.

[9] E. Bosi, F. Dotta, Y. Jia, and M. Goodman, "Vildagliptin plus metformin combination therapy provides superior glycaemic control to individual monotherapy in treatment-naive patients with type 2 diabetes mellitus," Diabetes, Obesity and Metabolism, vol. 11, no. 5, pp. 506-515, 2009.

[10] C. Filozof, S. Schwartz, and J. E. Foley, "Effect of vildagliptin as add-on therapy to a low-dose met formin," World Journal of Diabetes, vol. 1, no. 1, pp. 19-26, 2010.

[11] Novartis, Eucreas. Summary of Product Characteristics (UK).

[12] M. P. Hermans, C. Brotons, M. Elisaf, G. Michel, E. Muls, and F. Nobels, "Optimal type 2 diabetes mellitus management: the randomised controlled OPTIMISE benchmarking study: baseline results from six European countries," European Journal of Preventive Cardiology, vol. 20, no. 6, pp. 1095-1105, 2013.

[13] S. Bangalore, G. Kamalakkannan, S. Parkar, and F. H. Messerli, "Fixed-dose combinations improve medication complaince: a meta-analysis," American Journal of Medicine, vol. 120, no. 8, pp. 713-719, 2007.

[14] L. Blonde and Z. T. San Juan, "Fixed-dose combinations for treatment of type 2 diabetes mellitus," Advances in Therapy, vol. 29, no. 1, pp. 1-13, 2012.

[15] E. Bosi, R. P. Camisasca, C. Collober, E. Rochotte, and A. J. Garber, "Effects of vildagliptin on glucose control over 24 weeks in patients with type 2 diabetes inadequately controlled with metformin," Diabetes Care, vol. 30, no. 4, pp. 890-895, 2007. 


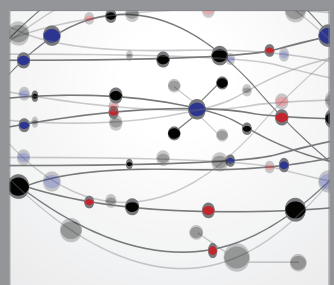

The Scientific World Journal


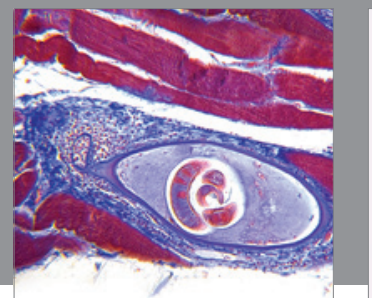

Gastroenterology

Research and Practice
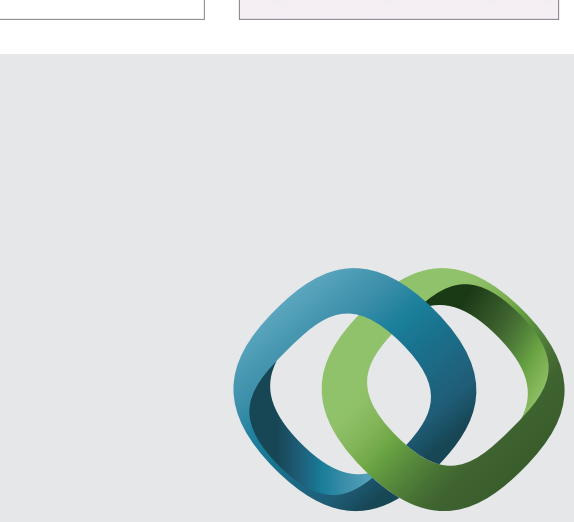

\section{Hindawi}

Submit your manuscripts at

http://www.hindawi.com
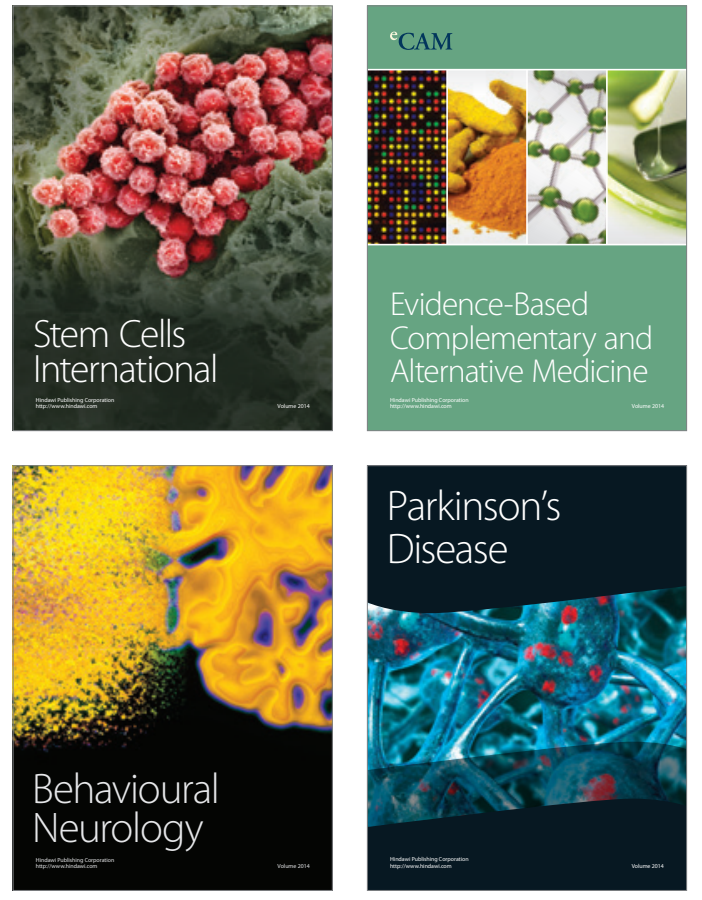
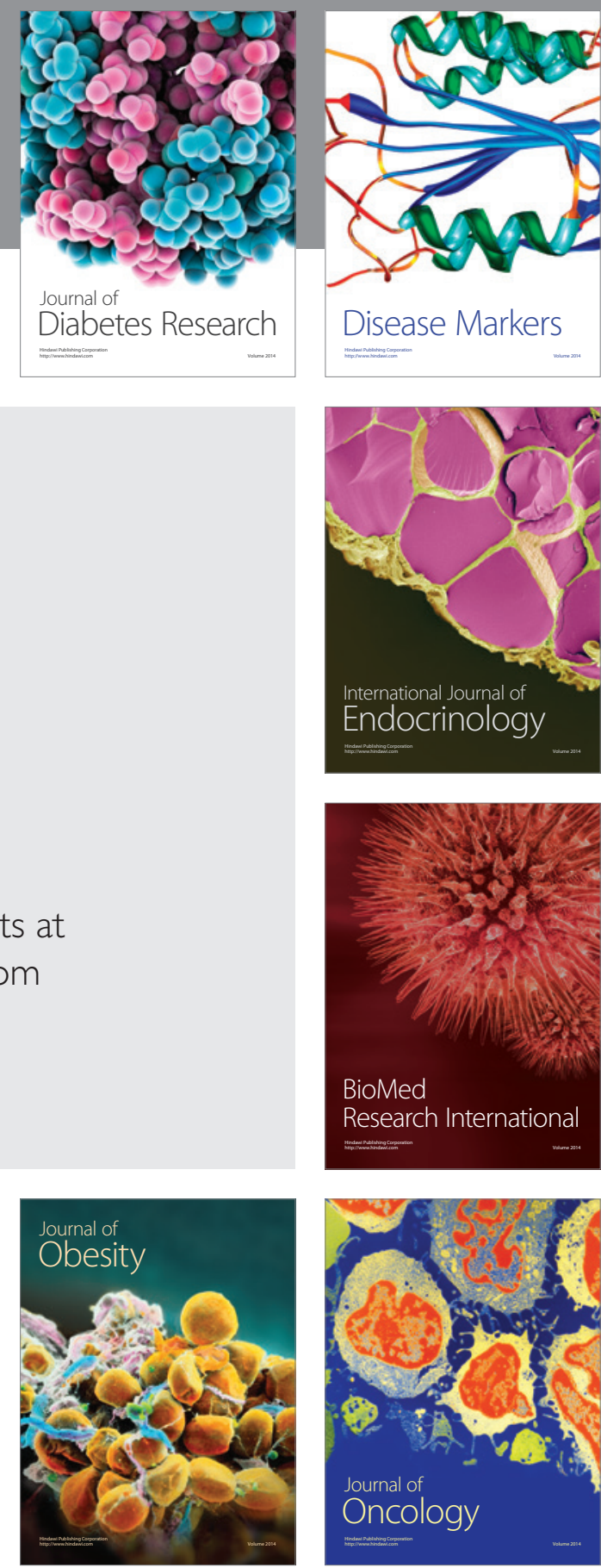

Disease Markers
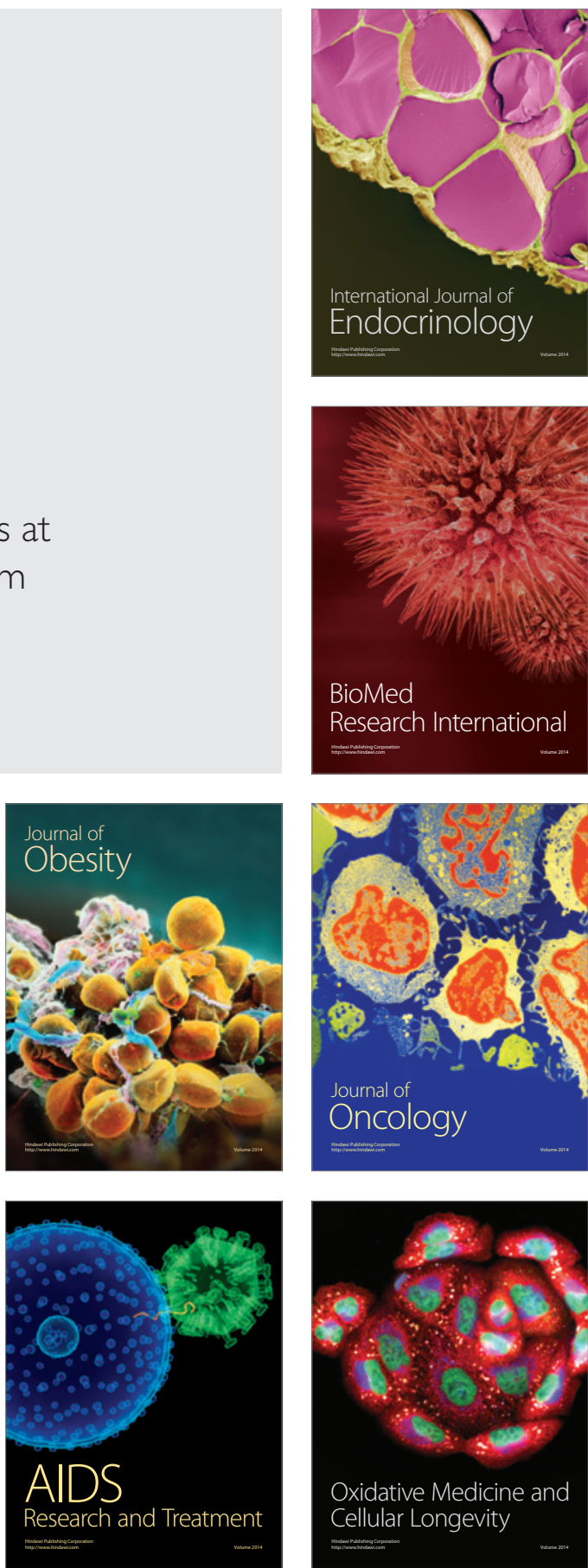